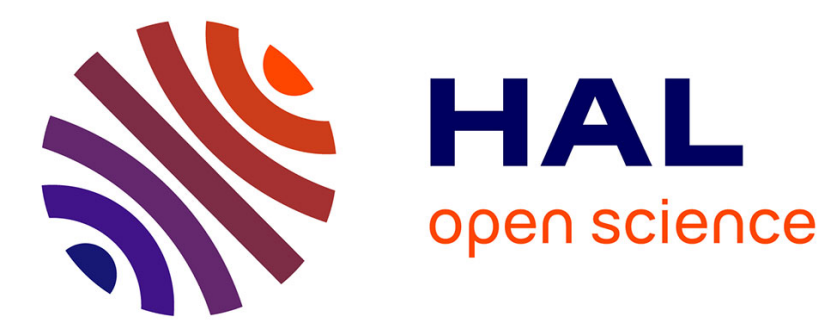

\title{
Impact of the equatorial deep jets on estimates of zonal transports in the Atlantic
}

\author{
C. Schmid, B. Bourles, Y. Gouriou
}

\section{To cite this version:}

C. Schmid, B. Bourles, Y. Gouriou. Impact of the equatorial deep jets on estimates of zonal transports in the Atlantic. Deep Sea Research Part II: Topical Studies in Oceanography, 2005, 52 (3-4), pp.409428. 10.1016/j.dsr2.2004.12.008 . hal-00409273

\section{HAL Id: hal-00409273 \\ https://hal.science/hal-00409273}

Submitted on 6 Apr 2020

HAL is a multi-disciplinary open access archive for the deposit and dissemination of scientific research documents, whether they are published or not. The documents may come from teaching and research institutions in France or abroad, or from public or private research centers.
L'archive ouverte pluridisciplinaire HAL, est destinée au dépôt et à la diffusion de documents scientifiques de niveau recherche, publiés ou non, émanant des établissements d'enseignement et de recherche français ou étrangers, des laboratoires publics ou privés. 


\title{
Impact of the equatorial deep jets on estimates of zonal transports in the Atlantic
}

\author{
C. Schmid ${ }^{\mathrm{a}, *}$, Bernard Bourlès ${ }^{\mathrm{b}}$, Yves Gouriou ${ }^{\mathrm{b}}$ \\ ${ }^{a}$ Atlantic Oceanographic and Meteorological Laboratory, National Oceanographic and Atmospheric Administration, \\ 4301 Rickenbacker Causeway, Miami, FL 33149, USA \\ ${ }^{\mathrm{b}}$ Centre IRD de Bretagne, BP 70, 29280 Plouzané, France
}

The structure and variability of the zonal equatorial flow in the Atlantic is studied on the basis of velocity profiles obtained with lowered Acoustic Doppler Current Profilers during multiple surveys. The vertical extent of the zonal currents is found to vary considerably. It can be as small as $100 \mathrm{~m}$ or as large as $1000 \mathrm{~m}$. In the Atlantic, vertical scales of 400-600 $\mathrm{m}$ have been associated with the equatorial deep jets (they are also frequently called deep jets or stacked jets). Typical amplitudes of the zonal velocity are about $20 \mathrm{~cm} \mathrm{~s}^{-1}$. An analysis of quasi-synoptic surveys indicates that the zonal extent of most jets is likely to be at least $27^{\circ}$. They can rise or deepen from west to east, although the deepening was observed more often and is often more pronounced. The west to east deepening can be as large as $320 \mathrm{~m} / 10^{\circ}$. Basinwide mean depth changes of the jets are mostly on the order of $50 \mathrm{~m} / 10^{\circ}$, and the largest depth changes are typically observed between $35^{\circ}$ and $23^{\circ} \mathrm{W}$. The existence of these changes indicates that vertically propagating, equatorially trapped, waves might be one cause for the jet structure. However, the dependence of the slope on the longitude indicates that other processes must be involved as well.

The typical vertical extent of the jets is small enough to result in several direction changes of the zonal flow in the Antarctic Intermediate Water (AAIW) and the North Atlantic Deep Water (NADW) layer. From transport estimates for 14 meridional sections it is found that the transport for the westward component of the flow within the AAIW layer $(500-1000 \mathrm{~m})$ can be as large as $-24 \mathrm{~Sv}\left(1 \mathrm{~Sv}=10^{6} \mathrm{~m}^{3} \mathrm{~s}^{-1}\right)$ within $1^{\circ}$ of the equator. For the eastward component of the flow in the AAIW layer the transport can be as large as $8 \mathrm{~Sv}$. Adding the transport components for each section results in a range of total AAIW transports from -24 to $7 \mathrm{~Sv}$. This suggest that the annual mean transport of AAIW is westward. The only months with eastward total transports are June and July. This is consistent with earlier Lagrangian and some other observations that indicated that the AAIW flow along the equator is governed by an annual cycle. In the NADW layer (1200-3900 m) the transport for the westward (eastward) flow can be as large as $-25 \mathrm{~Sv}$ ( $23 \mathrm{~Sv}$ ) within $1^{\circ}$ of the equator. This results in a range of total NADW transports from -10 to $18 \mathrm{~Sv}$. The variations of the total

\footnotetext{
*Corresponding author. Tel.: + 13053614313 ; fax: + 13053614412.

E-mail address: claudia.schmid@noaa.gov (C. Schmid).
} 
transports of AAIW and NADW are anti-correlated, with a correlation coefficient of -0.86 . Since only eight sections reached deep enough to allow transport estimates in the NADW layer it is more difficult to come to a conclusion about the mean transport in this layer than for the transport in the AAIW layer (for the latter layer 14 sections were available). Nevertheless, the obtained estimates suggest that the total NADW transport may be eastward.

Published by Elsevier Ltd.

\section{Introduction}

The zonal flow within about $1^{\circ}$ of the equator is characterized by equatorial deep jets of opposing zonal velocity in the Atlantic (e.g., Ponte et al., 1990), Indian (e.g., Luyten and Swallow, 1976) and Pacific Ocean (e.g., Eriksen, 1981). The equatorial deep jets are also frequently called deep jets, stacked jets, or simply jets. We will use the word jet throughout this study. Gouriou et al. $(1999,2001)$ reported that the vertical scale of the jets in the Atlantic is $400-600 \mathrm{~m}$, which is about $200 \mathrm{~m}$ larger than in the Pacific. Similar vertical scales were derived by Johnson and Zhang (2003) on the basis of hydrographic observations. For jets the typical peak-to-peak amplitude of the zonal velocity is on the order of $20 \mathrm{~cm} \mathrm{~s}^{-1}$. Less is known about the horizontal scales of these jets. Gouriou et al. $(1999,2001)$ found indications that the zonal scale may be similar to the $10-15^{\circ}$ observed in the Pacific and in the Indian Ocean (based on nonsynoptic data), and may even be as large as $25^{\circ}$. Gouriou et al. (2001) suggested that the jets are not established simultaneously over the whole water column, since they observed that the zonal coherence of the jets depended on the depth in the summer of 1999.

It is known that the structure of the jets varies significantly over time, but the time scales of this variability are only poorly understood, since contradictory observations exist. Some support seasonal reversals of the zonal flow below the Equatorial Undercurrent, for example: time series from current meter moorings in the western (Weisberg et al., 1980; Weisberg, 1980) and eastern Atlantic (Thierry, 2000), and the Pacific (Eriksen, 1981; 1985); Lagrangian observations at intermediate depth in the Atlantic (Richardson and Schmitz, 1993; Boebel et al., 1999; Molinari et al., 1999; Schmid et al., 2001); and evidence from velocity profiles in the Atlantic (Schott et al., 1998; Gouriou et al., 1999; Schott et al., 2003). Due to the nature of these observations it is hard to say if the seasonal reversals are due to the jets or due to currents with larger vertical scales than the jets. In addition, other observations do not support seasonal reversals, for example: observations in the Pacific do not show seasonal reversals of the jets or the flow, but the flow between 500 and $1700 \mathrm{~m}$ shifts from predominantly westward in April-July/1982 to predominantly eastward in April-July/1983 indicating that a large interannual variability may exist (Pegasus profiles from 21 cruises; Muench et al., 1994). Observations in the western Atlantic in October 1992 to May 1994 also do not show signs for seasonal reversals (four current meters between 1300 and $1900 \mathrm{~m}$ and Lowered Acoustic Doppler Current Profiler sections; Send et al., 2002).

In a modelling study Böning and Schott (1993) showed seasonal reversals of the flow below about $400 \mathrm{~m}$, which they linked to seasonal changes of the equatorial wind. They noted that the vertical scale of the flow in their model is larger than the vertical scale of the observed jets, which may be primarily due to a vertical grid resolution that is too large to resolve the jets $(250 \mathrm{~m}$ below a depth of $500 \mathrm{~m}$ ). Therefore, the model cannot be used to determine if the jets reverse on seasonal to interannual time scales.

Many studies have focused on finding dynamical explanations for the jets. Superpositions of Rossby and Kelvin waves with long periods can give rise to jet-like flow patterns (e.g., McCreary, 1984). One problem with this hypothesis is that the meridional extent of the resulting jets is larger than observed $\left(1.5^{\circ}\right.$ instead of $\left.1^{\circ}\right)$. Muench et al. (1994) showed that the addition of higher-frequency variability (e.g., Rossby-gravity waves with periods of 30-90 days) makes it possible to derive a 
meridional extent that matches the observations. Other problems with the linear wave theory are that: (1) it predicts that the jets are symmetrical around the equator (e.g., McCreary, 1984; Pedlosky, 2003), whereas the maximum velocity cores of the jets have been observed to be at an offequatorial position in some sections (e.g., Gouriou et al., 2001; Johnson et al., 2002). (2) This theory cannot explain how the jets are maintained for extended periods of time. As a mechanism for this, Muench and Kunze (2000) suggested that an ambient internal wave field which deposits momentum fluxes at critical layers within the deep jets can counteract the damping of the linear waves.

The generation of the jets also remains controversial. Suggested remote forcing mechanisms are: (1) surface forcing by the wind field (e.g., Wunsch, 1977). This is unlikely since the vertical group velocity is too small to generate and maintain the jets by surface forcing, even for weak dissipation (Muench and Kunze, 2000). Another problem is that a strong EUC can act as a barrier to vertically propagating waves. (2) Time-dependent boundary forcing, due to variability of the boundary currents (e.g., Ponte, 1989). (3) A specified zonal inflow form the boundary at the depth of the jets (Wang et al., 1994). Possibilities (2) and (3) are unlikely because the vertical scales of the jets do not match the vertical structure of the boundary currents and since there is no mechanism that can explain such a boundary forcing (Pedlosky, 2003). As an alternative to surface forcing Pedlosky (2003) suggested buoyancy forcing at the base of the mixed layer. A different line of thought suggests that local forcing by equatorial inertial instability (horizontal shear of the flow) can give rise to zonal flows of finite amplitude that have jet-like characteristics (Hua et al., 1997). If the flow is westward they have the maximum velocity off the equator, at the dynamical equator, which agrees better with the observations (e.g., Gouriou et al., 2001; Johnson et al., 2002).

In this study velocity sections obtained in the equatorial Atlantic over a period of 13 years will be analyzed. While many of the sections have been discussed before, a joint analysis of all these sections was never performed. It has to be cautioned, that the available extensive data set is not sufficient for a full dynamical analysis of the observed flow structures. However, some interesting insights can be gained through its analysis. One purpose of this study is to describe the zonal and vertical structures of the flow (Section 3.1). The temporal variability will be discussed on the basis of these observations and earlier results (Section 3.2). The implications of this variability for estimates of the transports of Antarctic Intermediate Water (AAIW) and North Atlantic Deep Water (NADW) along the equator will be addressed (Section 3.3). In Section 4 a comparison of the characteristics of the jets found in the observations with the flow structures expected from the various theories about the jets will be presented in an effort to increase the understanding of the jets. In this section the transport estimates will be discussed in conjunction with earlier results.

\section{Data and methods}

The data set used in this study consists of Eulerian velocities from Lowered Acoustic Doppler Current Profiler (LADCP) and Pegasus (only Cither 1) measurements in the tropical Atlantic obtained during 14 cruises from 1990 to 2002 (Fig. 1, Table 1). During most of the cruises crossequatorial sections were obtained. The only exception is the cruise performed in the summer of 1997 on board of the R.V. Seward Johnson during which a zonal section along the equator from $11^{\circ}$ to $38^{\circ} \mathrm{W}$ was completed with a station spacing between $2^{\circ}$ and $7^{\circ}$ (Fig. 2A). During the course of five cruises cross-equatorial sections were obtained at two or three different longitudes. Ten of the cruises crossed the equator at about $35^{\circ} \mathrm{W}$ (Table 1). Another profile on the equator at $35^{\circ} \mathrm{W}$ was obtained in July 1997 (R.V. Seward Johnson). Other longitudes with repeated equatorial profiles include $23^{\circ} \mathrm{W}$ (3 profiles) and $10-12.5^{\circ} \mathrm{W}$ (4 profiles).

Depth-averaged differences between LADCP velocities and Pegasus velocities are about $1 \mathrm{~cm} \mathrm{~s}^{-1}$, but below $1000 \mathrm{~m}$, the uncertainties of LADCP velocities are $3-5 \mathrm{~cm} \mathrm{~s}^{-1}$ (Hacker et al., 


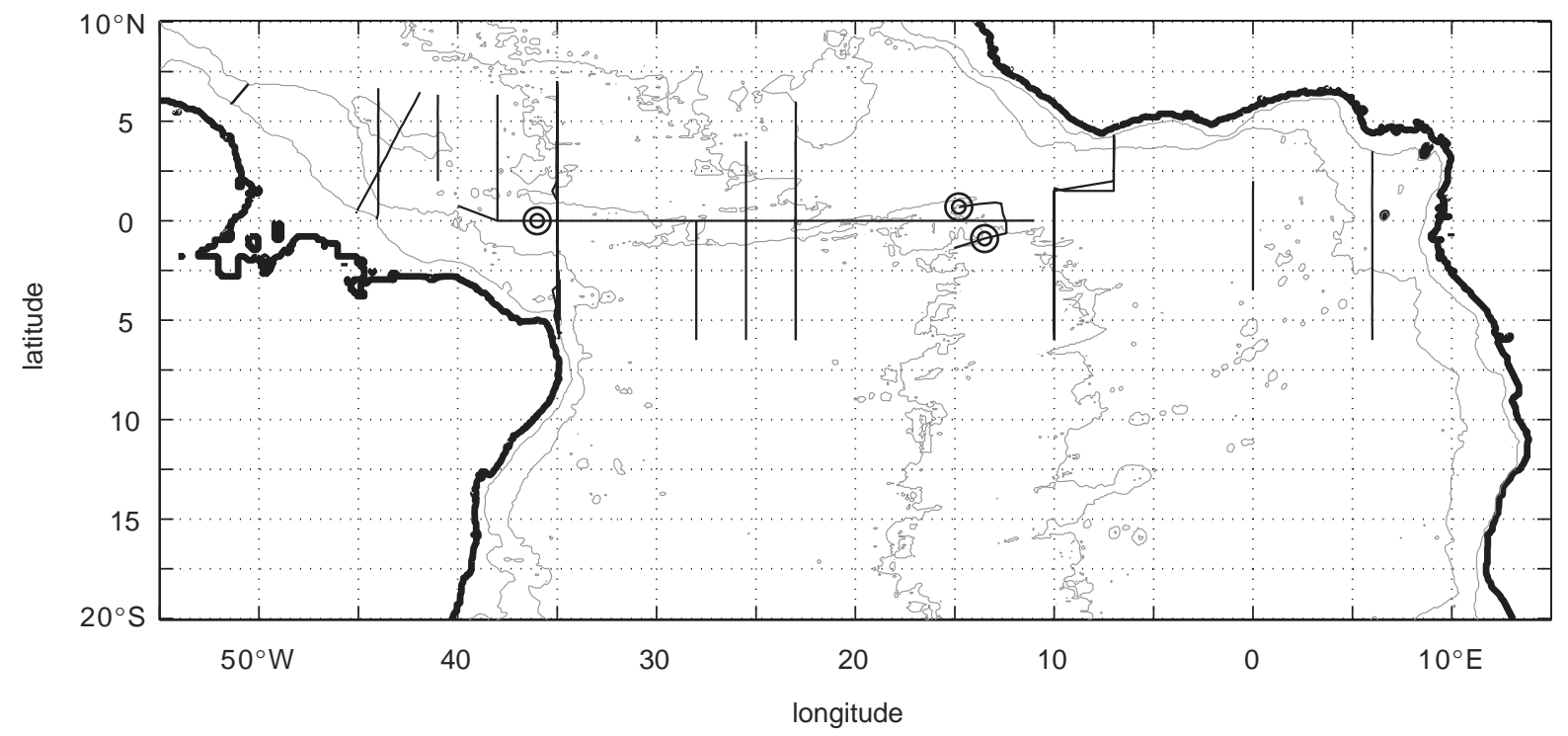

Fig. 1. Tracks of 15 cruises in the tropical Atlantic. The data were obtained in the years 1990-2002. The cruises are: R.V. Meteor 14/2, 10/1990; R.V. Meteor 16/3, 5-6/1991; R.V. Meteor 22/2, 11/1992; Cither 1, R.V. L'Atlante, 2/1993; R.V. Meteor 27/3, 3-4/1994; Romanche 3, 11/1994; Etambot 2, R.V. Edwig Link, 4/1996; R.V. Seward Johnson, 7/1997 (three zonal sections, $6^{\circ}$ S, equator, $6^{\circ}$ N); R.V. Equalant, R.V. La Thalassa, 7-8/1999; R.V. Seward Johnson, 1/2000; R.V. Meteor 47/1, 4/2000; R.V. Equalant, 7/2000; R.V. Oceanus 365/4, 3/2001; R.V. Ronald H. Brown, 2/2002. The longitudes of the sections are given in Table 1 . Two concentric circles indicate locations of current meter moorings maintained in 1992-1994. See Thierry (2000) for the two eastern moorings and Send et al. (2002) for the western mooring. The isobaths are 1000 and $4000 \mathrm{~m}$.

1996). This result is similar to the error of about $5 \mathrm{~cm} \mathrm{~s}^{-1}$ estimated by Fischer and Visbeck (1993). Herein we will assume that the measurement error is about $5 \mathrm{~cm} \mathrm{~s}^{-1}$.

The output from a global model of ocean tides was used to remove the barotropic tides from the velocity measurements. The method was also applied by Schmid et al. (2001), and the limitations were discussed therein. A justification for this correction is also given by Bourlès et al. (2003). The original model is described in detail in Egbert et al. (1994). The largest tidal corrections applied to the zonal velocities presented in this study are $4 \mathrm{~cm} \mathrm{~s}^{-1}$ and the mean correction is on the order of $1 \mathrm{~cm} \mathrm{~s}^{-1}$.

Throughout this study a peak-to-peak amplitude on the order of $20 \mathrm{~cm} \mathrm{~s}^{-1}$ and a vertical scale of 400-600 $\mathrm{m}$ (or alternatively a vertical distance to an adjacent velocity maximum of opposite sign if thick layers with only small velocity changes exist) is used to identify jets.

\section{Observations}

\subsection{Zonal and vertical structure}

Fig. 2 shows profiles of the zonal velocity obtained on the equator at different longitudes and times. The curvature of the velocity profiles is used to highlight westward anomalies in blue and eastward anomalies in red. In the summer of 1997 (Fig. 2A) five jets of varying thickness are present between the Equatorial Undercurrent and $1600 \mathrm{~m}$. The westward jets are centered near 250, 1100 and $1500 \mathrm{~m}$ and the eastward jets are centered near 400 and $1200 \mathrm{~m}$. A transition to another eastward jet is visible below $1500 \mathrm{~m}$. This pattern is interrupted by a thick layer of predominantly westward flow at intermediate depth (about 500-1000 m), where only small changes of the zonal velocity exist. The jet near $250 \mathrm{~m}$ is different from the other westward jets. While it has a pronounced westward anomaly in most profiles the total velocity is 
Table 1

The longitudes and times of 14 cruises are given

\begin{tabular}{|c|c|c|c|c|}
\hline Cruise & Time & Longitudes & Orientation & Instrument type \\
\hline R.V. Meteor $14 / 2$ & $10 / 1990$ & $35^{\circ} \mathrm{W}$ & Meridional & LADCP \\
\hline R.V. Meteor $16 / 3$ & $6 / 1991$ & $35^{\circ} \mathrm{W}$ & Meridional & LADCP \\
\hline R.V. Meteor $22 / 2$ & $11 / 1992$ & $35^{\circ} \mathrm{W}$ & Meridional & LADCP \\
\hline R.V. L'Atlante, Cither 1 & $2 / 1993$ & $35^{\circ} \mathrm{W}$ & Meridional & Pegasus \\
\hline R.V. Meteor $27 / 3$ & $3 / 1994$ & $35^{\circ} \mathrm{W}$ & Meridional & LADCP \\
\hline Romanche 3 & $11 / 1994$ & $12.5^{\circ} \mathrm{W}$ & Meridional & LADCP \\
\hline R.V. Edwig Link, Etambot 2 & $4 / 1996$ & $35^{\circ} \mathrm{W}$ & Meridional & LADCP \\
\hline R.V. Seward Johnson & $7-8 / 1997$ & $11-38^{\circ} \mathrm{W}$ & Zonal & LADCP \\
\hline R.V. La Thalassa; R.V. Equalant & $7-8 / 1999$ & $10,23,35^{\circ} \mathrm{W}$ & Meridional & LADCP \\
\hline R.V. Seward Johnson & $1 / 2000$ & $23,25.5,28^{\circ} \mathrm{W}$ & Meridional & LADCP \\
\hline R.V. Meteor 47/1 & $4 / 2000$ & $35^{\circ} \mathrm{W}$ & Meridional & LADCP \\
\hline R.V. Equalant & $7 / 2000$ & $6^{\circ} \mathrm{E}, 0^{\circ}, 10^{\circ} \mathrm{W}$ & Meridional & LADCP \\
\hline R.V. Oceanus 365/4 & $3 / 2001$ & $35,38^{\circ} \mathrm{W}$ & Meridional & LADCP \\
\hline R.V. Ronald H. Brown & $2 / 2002$ & $35,44^{\circ} \mathrm{W}$ & Meridional & LADCP \\
\hline
\end{tabular}

The column 'orientation' indicates if zonal or meridional sections were taken, LADCP stands for Lowered Acoustic Doppler Current Profiler.

sometimes eastward, which may be due to the close proximity to the Equatorial Undercurrent.

Three of the five jets (those between 1000 and $1600 \mathrm{~m}$ ) are clearly visible throughout the $27^{\circ}$ long section (the gradual change of the jet depths is discussed below). The two shallowest jets, near 250 and $400 \mathrm{~m}$, can be seen clearly from $38^{\circ}$ to $15^{\circ} \mathrm{W}$, both in the original and in the smoothed profiles. At $11^{\circ} \mathrm{W}$ these jets cannot be found in the smoothed profiles, but small anomalies with the correct curvature can be seen in the original profiles. The one corresponding to the $250 \mathrm{~m}$ jet is just above $250 \mathrm{~m}$. The other one is at $250 \mathrm{~m}$, i.e. about $150 \mathrm{~m}$ shallower than the corresponding jet in the other profiles. The weakness of these anomalies is intriguing because they could be, e.g., indicative for the formation or break-down of the jets.

Two years later (Fig. 2B) the structure differs significantly from the pattern observed in the summer of 1997. In 1999 the peak-to-peak amplitudes of the zonal velocity and the distances between them are generally more regular than in 1997. In addition, one more jet is observed between the Equatorial Undercurrent and $1600 \mathrm{~m}$ in 1999 (a direct comparison of selected profiles obtained at three different longitudes during these two cruises can be found in Figs. 3 and 4). Between 200 and $2100 \mathrm{~m}$ the jet structure is very regular, with the peak to peak distance in the range of 200-300 m. Below $2100 \mathrm{~m}$ the peak-to-peak amplitudes are smaller and the vertical scale is more variable (not shown).

In January 2000 the flow pattern again deviates from the earlier observations (Fig. 2C; a direct comparison of the $23^{\circ} \mathrm{W}$ profile with other profiles obtained at the same longitude is shown in Fig. 4A). Two quite broad currents (we do not call them jets because of their large vertical extent) exist between the Equatorial Undercurrent and 

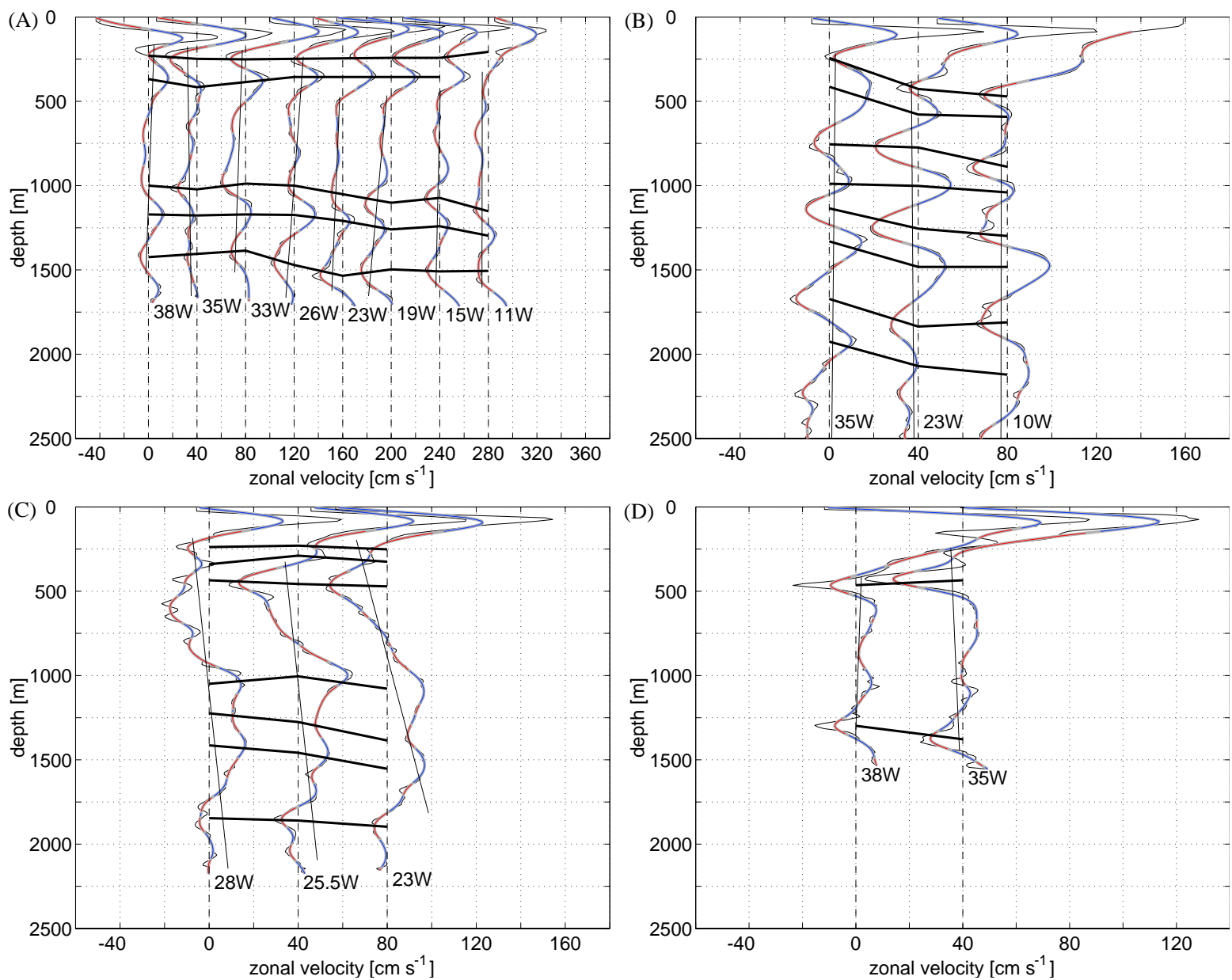

Fig. 2. Profiles of the zonal velocity on the equator from ADCP observations: (A) 19-25 July 1997, (B) 24 July-15 August 1999, (C) 16-24 January 2000, (D) 7-13 March 2001. The profiles are shifted by $40 \mathrm{~cm} \mathrm{~s}^{-1}$, and the zero velocity for each profile is shown as a dashed line. The thin solid line overlaid over each profile indicates the large-scale vertical slope of the flow (the Equatorial Undercurrent has been excluded in the derivation of the slope). The thick gray lines show the velocity profiles after low-pass-filtering with a Butterworth filter using a cut-off length scale of $100 \mathrm{~m}$. The thick black lines mark features that can be traced from profile to profile. Red (blue) segments of the profiles indicate layers with positive (negative) curvatures, which are frequently associated with westward (eastward) jets.

about $1800 \mathrm{~m}$. Superimposed on them are variabilities with smaller scales. The shallower current has a relatively pointed westward peak at about $400 \mathrm{~m}$ in the smoothed curves for two of the profiles, whereas the maximum is significantly wider in the smoothed profile at $28^{\circ} \mathrm{W}$. The original profile has nine small peaks with a vertical distance in the range of about $100-200 \mathrm{~m}$ that are superimposed on the westward current. Three of these peaks can be associated with small peaks in the other two profiles (as indicated by black lines). The shallower two of these anomalies are strong enough to remain visible in the smoothed profiles. The deeper eastward current has two relative maxima of the eastward velocity near 1000 and $1500 \mathrm{~m}$ that are separated by a minimum near $1300 \mathrm{~m}$. The corresponding vertical scale of $500 \mathrm{~m}$ is typical for jets. However, the mean peak-to-peak amplitude is less than $10 \mathrm{~cm} \mathrm{~s}^{-1}$ which is significantly smaller than the typical peak-to-peak 
amplitude of jets. Below these two currents a weak westward peak exists near $1800 \mathrm{~m}$ at $23^{\circ}$ and $25.5^{\circ} \mathrm{W}$. At $28^{\circ} \mathrm{W}$ two westward peaks exist around this depth.

In March 2001 the jets are even more poorly developed than in the summer of 1997 (Fig. 2D; for a direct comparison of $35^{\circ} \mathrm{W}$ profiles see Fig. $3)$. The most prominent features are two westward jets at 400 and $1300 \mathrm{~m}$. Even so the variability of the primarily eastward velocity is quite weak, this variability is sufficient to classify both currents as jets since they are about $200 \mathrm{~m}$ away from a maximum eastward velocity and have a sufficiently large velocity anomaly. A minimum of the eastward flow can be identified at a depth of $800 \mathrm{~m}$ at $38^{\circ} \mathrm{W}$. A similar minimum exists at $35^{\circ} \mathrm{W}$ (the velocity actually changes sign, but it is only weakly westward). As in January 2000 several peaks of small peak-to-peak amplitude (less than $10 \mathrm{~cm} \mathrm{~s}^{-1}$ ) and small vertical scale (about $100 \mathrm{~m}$ ) are observed, only this time they are located between 800 and $1200 \mathrm{~m}$.

While the velocity profiles obtained in the four surveys differ considerably, they all indicate that changes of the depth of the jets (and some of the other peaks) exist. They are marked with thick black lines in Fig. 2. Throughout this study depth changes are always described in the Eulerian sense. That means the direction of the flow is disregarded. I.e. a jet can shoal from west to east, even if the velocity within the jet is westward. The depth changes listed in Table 2 were estimated by subtracting the two depths of a jet as observed at the eastern and western end of a section, respectively. The resulting value is then divided by the distance in degrees longitude and normalized to be representative for a zonal distance of $10^{\circ}$.

In the summer of 1997 (Fig. 2A) the shallowest two jets shoaled, on average, from west to east by 5- $8 \mathrm{~m} / 10^{\circ}$ (Table 2). The three jets below $1000 \mathrm{~m}$ deepened from west to east by $44 \pm 13 \mathrm{~m} / 10^{\circ}$ (the given error is the standard deviation). It is noted that the depth changes of these jets depend on the longitude. For the deepest jet, near $1500 \mathrm{~m}$, the depth change is quite large between $33^{\circ}$ and $23^{\circ} \mathrm{W}$, whereas the depth change outside of this longitude range is rather small and sometimes even of opposite sign (i.e. the jet may be shoaling slightly towards the east instead of deepening). For the jets near 1000 and $1200 \mathrm{~m}$ large depth changes are observed in the longitude range $26-19^{\circ} \mathrm{W}$, which fits nicely to the characteristics of the deepest jet near $1500 \mathrm{~m}$. However the two shallower jets also experience large depth changes between $15^{\circ}$ and $11^{\circ} \mathrm{W}$. In the summer of 1999 no shoaling jet is observed. Instead the eight clearly identifiable jets are deepening from west to east, with a mean depth change of $62 \pm 21 \mathrm{~m} / 10^{\circ}$. Consistent with the observations in 1997 most of the deepening occurs between the two western profiles $\left(35^{\circ}\right.$ and $23^{\circ} \mathrm{W}$ ). The only exception are the two jets near 750 and $1000 \mathrm{~m}$. In January 2000 six of the seven velocity peaks (as mentioned above none of these peaks has the characteristics typical for jets) are deepening from west to east by $28-322 \mathrm{~m} / 10^{\circ}$ (Table 2). Only the poorly defined peak near $300 \mathrm{~m}$ shoals slightly. The mean depth change of the six deepening peaks is $143 \mathrm{~m} / 10^{\circ}$ with a standard deviation of $124 \mathrm{~m} / 10^{\circ}$. The relatively large depth changes encountered below $1100 \mathrm{~m}$ between $28^{\circ}$ and $23^{\circ} \mathrm{W}$, the full zonal extent of the survey, is consistent with the observations in the two earlier surveys. In March 2001 the upper westward jet shoals from $38^{\circ}$ to $35^{\circ} \mathrm{W}$, whereas the lower jet deepens. Both, the shoaling and the deepening, are about twice as large as the maximum shoaling and deepening observed in the same longitude range in the summer of 1997. Because of the limited zonal extents of the January 2000 and the March 2001 surveys the relative large slopes, derived primarily below $1100 \mathrm{~m}$, cannot be seen as representative for basin-scale depth changes. Taken together, these observations suggests that west-east deepening of the jets (and peaks) occurs more frequently than west-east shoaling. In addition, west-east shoaling can primarily be detected at shallower depths (between the Equatorial Undercurrent and $500 \mathrm{~m}$ ).

\subsection{Temporal variability}

Eleven profiles obtained at $35^{\circ} \mathrm{W}$ (Fig. 3) are available to analyze the variability of the zonal velocity in the upper $2000 \mathrm{~m}$. In addition, three profiles at $23^{\circ} \mathrm{W}$ (Fig. 4A) and four profiles in $10-12.5^{\circ} \mathrm{W}$ (Fig. 4B) were obtained at different times. 

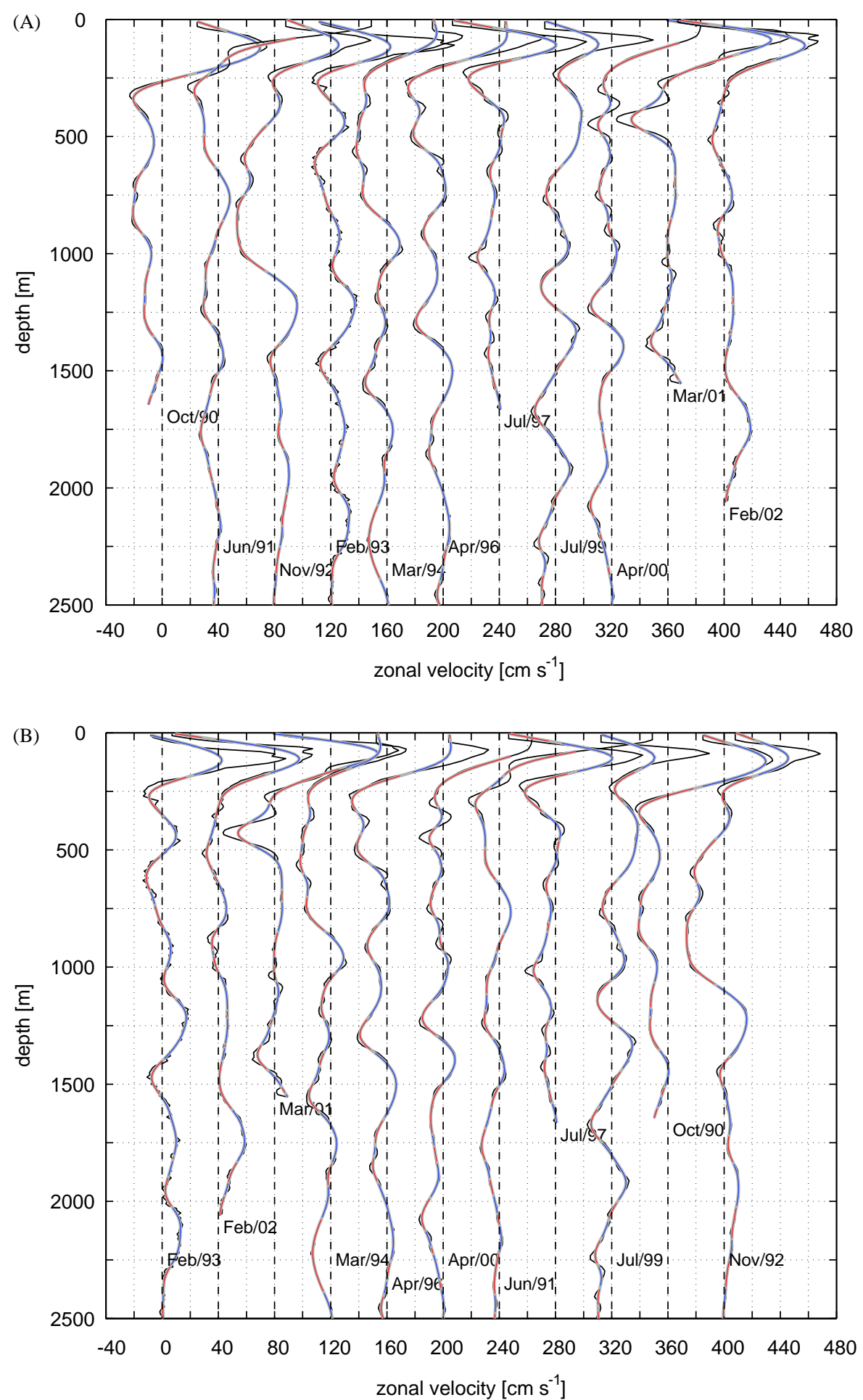

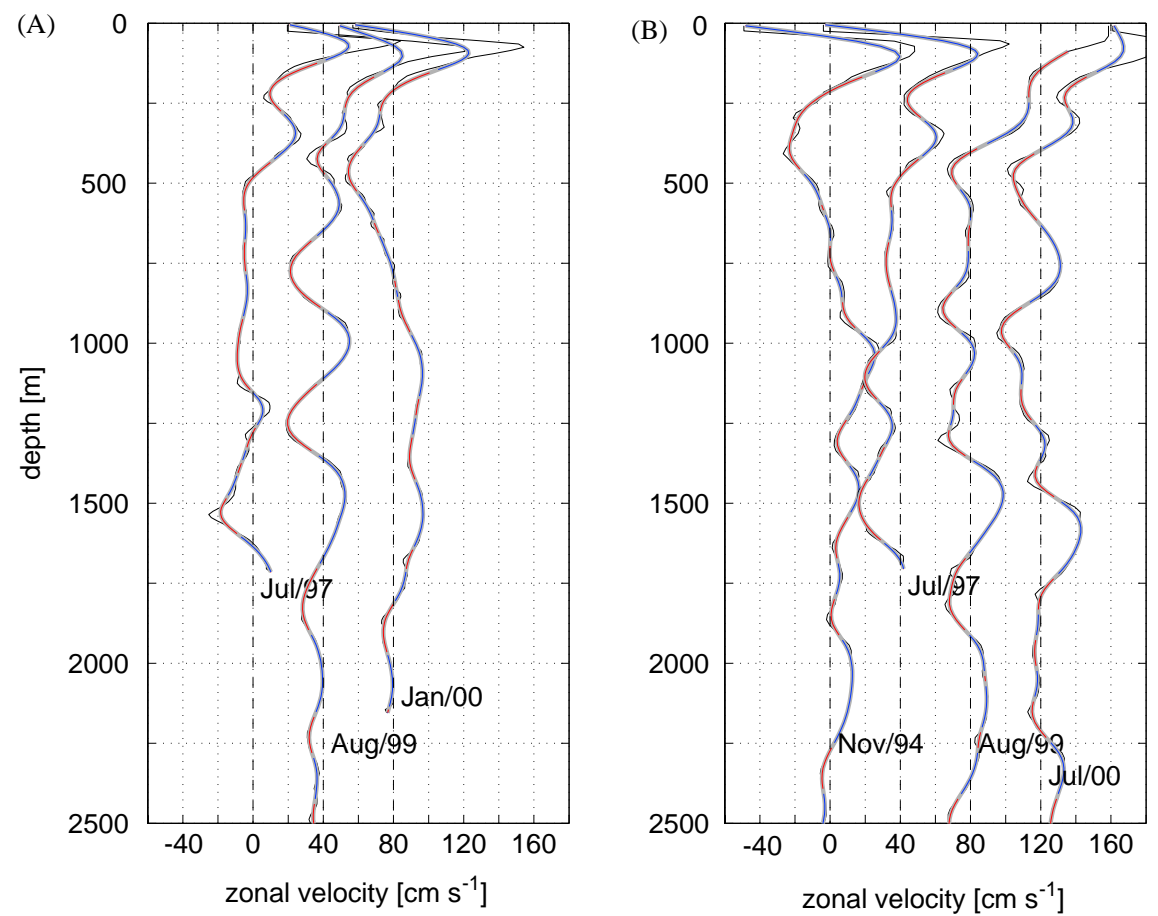

Fig. 4. Profiles of the zonal velocity on the equator at $23^{\circ} \mathrm{W}(\mathrm{A})$ and in $10-12.5^{\circ} \mathrm{W}$ (B) from observations with lowered ADCPs. The profiles are shifted by $40 \mathrm{~cm} \mathrm{~s}^{-1}$, and the zero velocity for each profile is shown as a dashed line. The smoothed profiles (thicker gray lines with red and blue overlaid) were obtained by applying a low-pass Butterworth filter with a cut-off length scale of $100 \mathrm{~m}$. Red (blue) segments of the profiles indicate layers with positive (negative) curvatures, which are frequently associated with westward (eastward) jets.

As mentioned in Section 3.1, in some of these profiles the jet structure is strongly developed (e.g., July 1999, April 1996 and February 1993), whereas other profiles have fewer, poorly developed jets with smaller peak-to-peak amplitudes (e.g., July 1997, March 2001). Differences between the jets observed at different times can be characterized as belonging to one of three general categories. At given depths the profiles can have jets pointing in the same direction, they can have opposing jets, or one profile has a zero crossing while the velocity in the other profile is almost at its maximum within a jet. All three configurations can be observed in a comparison of two profiles. A good example are the profiles obtained at $35^{\circ} \mathrm{W}$ in February 1993 and March 1994 (Fig. 3A): near $800 \mathrm{~m}$ an eastward jet exists in both profiles. Just below $1000 \mathrm{~m}$ a westward jet exists in February 1993 (note: this jet can only be identified by the curvature, the total velocity remains weakly eastward in the smoothed profile), whereas a zero crossing was observed in March 1994. Near $2200 \mathrm{~m}$ the jets are of opposite sign.

It is also found that none of the profiles obtained within a 1-year long period have matching jets throughout the water column between the Equatorial Undercurrent and the maximum common depth (Fig. 3A). The same is observed for the

Fig. 3. Profiles of the zonal velocity on the equator at $35^{\circ} \mathrm{W}$ from observations with lowered ADCPs (Pegasus in February 1993): (A) by date, (B) by month. The profiles are shifted by $40 \mathrm{~cm} \mathrm{~s}^{-1}$, and the zero velocity for each profile is shown as a dashed line. The smoothed profiles (thicker gray lines with red and blue overlaid) were obtained by applying a low-pass Butterworth filter with a cut-off length scale of $100 \mathrm{~m}$. Red (blue) segments of the profiles indicate layers with positive (negative) curvatures, which are frequently associated with westward (eastward) jets. 
Table 2

Mean depth changes of equatorial deep jets (or velocity peaks if the vertical scale or amplitude differs from those typical for jets), based on the full longitude range of each survey are given

\begin{tabular}{lcl}
\hline Cruise & $\begin{array}{c}\text { Depth } \\
(\mathrm{m})\end{array}$ & $\begin{array}{l}\text { Depth } \\
\text { change }\left(\mathrm{m} / 10^{\circ}\right)\end{array}$ \\
\hline Seward Johnson 1997 & 237 & -8 \\
Seward Johnson 1997 & 374 & -5 \\
Seward Johnson 1997 & 1049 & 56 \\
Seward Johnson 1997 & 1213 & 47 \\
Seward Johnson 1997 & 1475 & 30
\end{tabular}

Mean west-east shoaling: $-7 \mathrm{~m} / 10^{\circ}$, std.dev.: $2 \mathrm{~m} / 10^{\circ}$

Mean west-east deepening: $44 \mathrm{~m} / 10^{\circ}$, std.dev.: $13 \mathrm{~m} / 10^{\circ}$

$\begin{array}{lrl}\text { Equalant } 1999 & 380 & 91 \\ \text { Equalant } 1999 & 528 & 71 \\ \text { Equalant } 1999 & 806 & 53 \\ \text { Equalant } 1999 & 1010 & 20 \\ \text { Equalant } 1999 & 1230 & 66 \\ \text { Equalant } 1999 & 1432 & 60 \\ \text { Equalant } 1999 & 1773 & 56 \\ \text { Equalant } 1999 & 2039 & 78\end{array}$

Mean west-east deepening: $62 \mathrm{~m} / 10^{\circ}$, std.dev.: $21 \mathrm{~m} / 10^{\circ}$

$\begin{array}{lrr}\text { Seward Johnson 2000 } & 240 & 28 \\ \text { Seward Johnson 2000 } & 318 & -30 \\ \text { Seward Johnson 2000 } & 454 & 72 \\ \text { Seward Johnson 2000 } & 1044 & 58 \\ \text { Seward Johnson } 2000 & 1295 & 322 \\ \text { Seward Johnson 2000 } & 1475 & 278 \\ \text { Seward Johnson 2000 } & 1868 & 102\end{array}$

Mean west-east deepening: $143 \mathrm{~m} / 10^{\circ}$, std.dev.: $124 \mathrm{~m} / 10^{\circ}$

$\begin{array}{lrr}\text { Oceanus } 2001 & 450 & -97 \\ \text { Oceanus } 2001 & 1338 & 267\end{array}$

For easier comparison all estimates are normalized to be representative for a zonal distance of $10^{\circ}$. Jets (or peaks for the Seward Johnson 2000 survey) that are deepening (shoaling) from west to east have positive (negative) values. The means and standard deviations are derived separately for the deepening and shoaling jets (or peaks) observed in the individual surveys.

profiles obtained in the same month or season of different years (Fig. 3B). Some profiles support the presence of an annual cycle, e.g., at $500 \mathrm{~m}$ a slight preference for westward flow and westward jets can be detected in February-April. In July-October the profiles indicate that a preference for eastward flow and eastward jets is possible. However, some profiles do not fit into this pattern, e.g., February 1993 and July 1997. This indicates that other time scales must also play an important role. The temporal variability will be discussed more extensively later, based on estimates of the zonal transport.

\subsection{Zonal transports}

The transports for two water masses will be estimated based on the layer definitions presented in Fig. 5. This figure shows the zonal velocity across three meridional sections between $28^{\circ}$ and $23^{\circ} \mathrm{W}$ in January 2000 and selected water mass boundaries. The upper and lower boundaries of the AAIW layer are given by the isopycnals 27.1 and $27.4 \mathrm{~kg} \mathrm{~m}^{-3}$ (thick solid lines; Stramma and England, 1999). The core of this water mass is at the depth with the lowest salinity (line with circles). At all three longitudes this layer extends from about 500 to about $1000 \mathrm{~m}$ on the equator. The upper limit of the NADW layer is given by the isopycnal marking the depth where the density $\sigma_{2}$ is $36.65 \mathrm{~kg} \mathrm{~m}^{-3}$ (Stramma and England, 1999), near $1200 \mathrm{~m}$. The lower limit of the NADW layer, when defined as the depth of the isopycnal $\sigma_{2}=37.05 \mathrm{~kg} \mathrm{~m}^{-3}$, is at about $3900 \mathrm{~m}$ (not shown). Before deriving the transports for these two water masses the structure of the zonal velocity will be analyzed.

\subsubsection{Antarctic intermediate water (AAIW)}

A major difference between the velocity in the AAIW layer of the three sections in Fig. 5 is that at $28^{\circ} \mathrm{W}$ in the equatorial band $\left(1^{\circ} \mathrm{S}-1^{\circ} \mathrm{N}\right)$ the whole layer was governed by westward flow (associated with the westward current centered at about $600 \mathrm{~m}$, Fig. 2C), whereas the portion with westward flow was reduced to $75 \%$ at $25.5^{\circ} \mathrm{W}$ and $50 \%$ at $23^{\circ} \mathrm{W} .{ }^{1}$ Other surveys also reveal significant

\footnotetext{
${ }^{1}$ Only the southern half of the equatorial band was covered with measurements in the $28^{\circ} \mathrm{W}$ section. However, due to the nearly symmetric structure of the equatorial currents and jets, with respect to their vertical extent, it is no problem to speak about the equatorial band in this context.
} 
changes of the flow structure along the equator in this layer. For example, in July 1997 (Fig. 2A) the flow is westward throughout this layer in six out of eight profiles. At $15^{\circ} \mathrm{W}$ the flow is eastward in the lower half of the layer with a peak velocity of $7.4 \mathrm{~cm} \mathrm{~s}^{-1}$, and at $26^{\circ} \mathrm{W}$ the flow is eastward in a thin slab with a peak velocity of $5.3 \mathrm{~cm} \mathrm{~s}^{-1}$. Both of these values are larger than the measurement error associated with LADCP data.

At $35^{\circ} \mathrm{W}$ (Fig. 3) three profiles reveal purely westward flow in the AAIW layer (October 1990, November 1992 and July 1997). Eastward flow throughout most of the AAIW layer is observed in only one profile (March 2001). The other seven $35^{\circ} \mathrm{W}$ profiles reveal alternating flow within the AAIW layer: In July 1999 westward flow in the AAIW core is surrounded by eastward flow in the upper and lower part of the AAIW layer. The opposite is the case in June 1991 and February 2002, with eastward flow in the core and westward flow above and below the core. In two other profiles (February 1993, March 1994) the upper part of the AAIW layer has westward velocities, whereas eastward velocities are observed in the lower part of this layer.

The components and the total zonal transports across four longitudes, nominally between $1^{\circ} \mathrm{S}$ and $1^{\circ} \mathrm{N},{ }^{2}$ are given in Table 3. In addition, Fig. 6 shows the cumulative transports at $35^{\circ} \mathrm{W}$ (integrated from top to bottom). In the AAIW layer $(500-1000 \mathrm{~m})$ at $35^{\circ} \mathrm{W}$ the largest eastward transport is $7.8 \mathrm{~Sv}\left(1 \mathrm{~Sv}=10^{6} \mathrm{~m}^{3} \mathrm{~s}^{-1}\right)$ and the largest westward transport is $-24.3 \mathrm{~Sv}$. The two sections without any eastward transport have large total westward transports and were obtained in the same season (October/November). The largest eastward and smallest westward transports were observed in two summer surveys (June 1991/July 1999), which results in a total eastward transport. All surveys taken together support earlier studies

\footnotetext{
${ }^{2}$ Some of the sections do not cover the full latitude range, as indicated in the last column of Table 3 . In this context the meridional asymmetry of the currents and jets due to the often off-equatorial location of the velocity maximum cannot be ignored. Therefore, only sections that have observations on both sides of the equator were used for the transport estimates. For the sections that do not cover the equatorial band fully the transports are likely to be underestimated.
}

which concluded that an annual cycle exists (see Section 4), and that the annual mean of the total transport of AAIW may be westward. The latter can be inferred since most months are governed by westward flow and the westward transports can be significantly larger than the largest eastward transports. Interannual variability must also play a role: while no zonal transports could be estimated for the zonal section in July 1997 the flow in the AAIW layer is predominantly westward at most longitudes. Therefore, it can be deduced that the July 1997 transport in the AAIW layer would be in the opposite direction than the transport in July 1999.

As already indicated by the depth changes of the jets and peaks highlighted in Fig. 2 a significant longitude dependence of the transports exists. Two examples, January 2000 and July 1999, are given in Table 3 . In the January survey the total transport changes from westward in the two western sections to small and eastward in the easternmost section. In the July survey the total transport changes from eastward at $35^{\circ} \mathrm{W}$ to a negligible transport at $23^{\circ} \mathrm{W}$.

\subsubsection{North Atlantic deep water (NADW)}

As in the AAIW layer alternating zonal velocities are common in the NADW layer. The likelihood for this to occur is even larger than in the AAIW layer, because the NADW layer occupies a significantly larger chunk of the water column.

When comparing the transport estimates it has to be kept in mind that some of the profiles within $1^{\circ}$ of the equator do not reach the lower limit of the NADW layer at $3900 \mathrm{~m}$ (sections where this is the case are indicated in Table 3). The meridional integration of the transports shown in Fig. 6 was terminated at the depth where more than two profiles did not have velocity data. For the vertically integrated transports this lack of data will lead to an error of the westward and/or eastward transport components. The transports around this depth are smaller than those above and, typically, only about $10 \%$ of the data in one profile are not available. From Fig. 6 it can be seen that the error for the components of the transports across a section caused by this lack of data is 
mostly small. In April 1996 the total transport is basically negligible, and the shape of the curve indicates that this is unlikely to change if the full depth profiles had been measured. Similarly, the April 2000 transport does not change much near $4000 \mathrm{~m}$. For the July 1999 survey it can be deduced
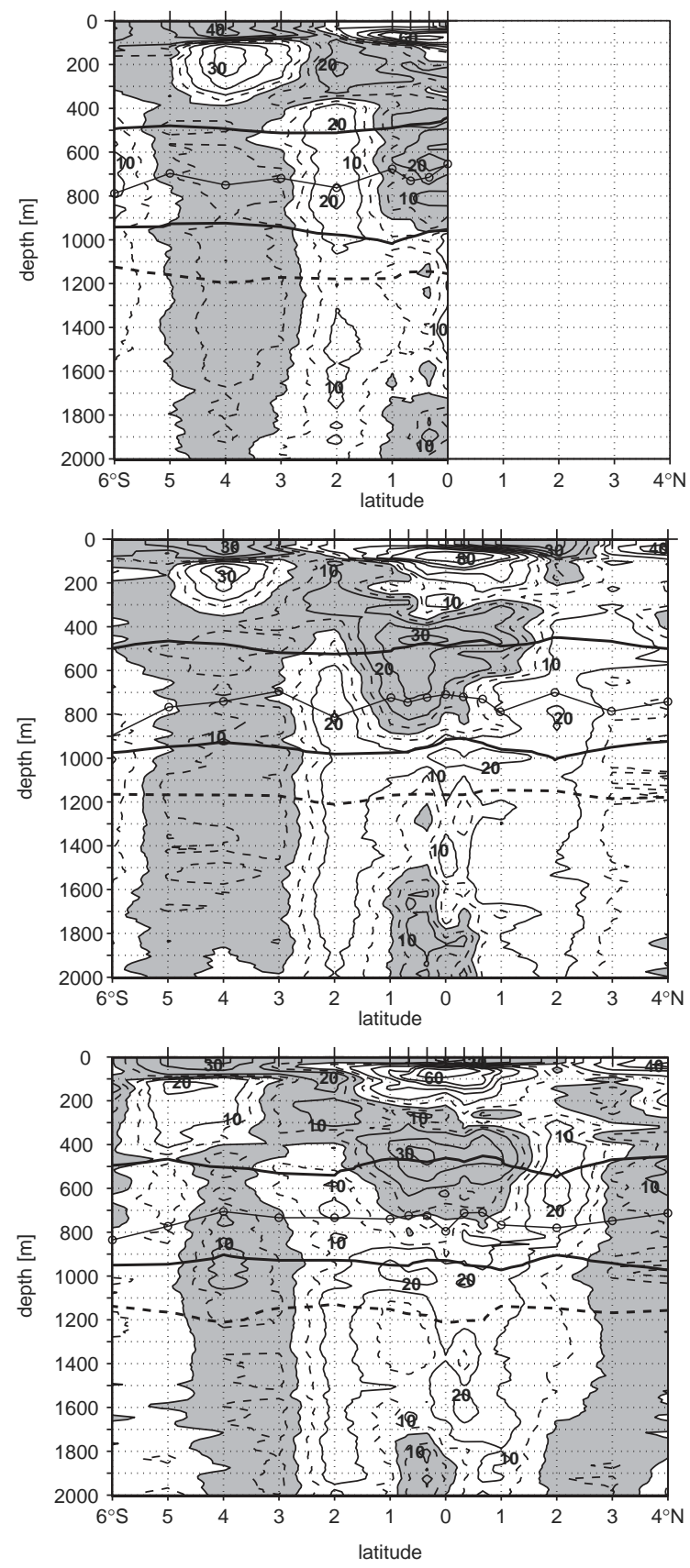

that the actual westward transport is smaller than the one given in Table 3 .

The transports of NADW range from -24.9 to $22.7 \mathrm{~Sv}$ when eastward and westward flow is treated separately. Even though only relatively few transport estimates are available the observations indicate that an annual cycle may exist. The smallest westward transports of NADW $(-10.0 \mathrm{~Sv}$ or less) are found in the winter (November, February, Table 3). The smallest eastward transports are observed in April and in June/July. The latter are also the months with the largest westward transports. This results in total transports that have a westward maximum in June/July (about $-10 \mathrm{~Sv}$ ) and an eastward maximum in November (about $18 \mathrm{~Sv})$. The transition between these two distinct seasons occurs in spring (March/April, with an eastward transport that is less than $1 \mathrm{~Sv}$, with the exception of $-5.5 \mathrm{~Sv}$ in April 2000) and in the late summer or early fall (not enough data are available to be more precise). It is noteworthy, that the eastward maximum of the total NADW transport coincides with the westward maximum of the total AAIW transport, and that the largest total westward NADW transport was derived for a month when the total AAIW transport is eastward. Overall the annual cycle of the NADW transport is anticorrelated with the AAIW transport (the correlation coefficient is -0.86 ).

\section{Discussion and conclusions}

Vertical scales ranging from 100 to $1000 \mathrm{~m}$ are observed in equatorial profiles of the zonal

Fig. 5. Sections of the zonal velocity from lowered ADCP measurements at $28^{\circ} \mathrm{W}$ (top, 22-23 January 2000) $25.5^{\circ} \mathrm{W}$ (middle, 14-16 January 2000) and $23^{\circ} \mathrm{W}$ (bottom, 17-20 January 2000). The $5 \mathrm{~cm} \mathrm{~s}^{-1}$ isoline is dashed. The two thick lines show the depths where the density $\left(\sigma_{\Theta}\right)$ is 27.1 and $27.4 \mathrm{~kg} \mathrm{~m}^{-3}$ to indicate the upper and lower boundary of the Antarctic Intermediate Water (AAIW) layer. The thin line with circles marks the salinity minimum of the AAIW. The thick dashed line shows the depth where the density $\left(\sigma_{2}\right)$ is $36.65 \mathrm{~kg} \mathrm{~m}^{-3}$ to indicate the upper boundary of the North Atlantic Deep Water layer. Tic marks at the top of each panel indicate the profile locations. The equatorial profiles for these sections are shown in Fig. 2C. 
Table 3

Zonal transports within $1^{\circ}$ of the equator in the AAIW layer (500-1000 m) and in the NADW layer (1200-3900 m)

\begin{tabular}{|c|c|c|c|c|c|c|c|}
\hline \multirow[t]{2}{*}{ Date } & \multicolumn{3}{|c|}{ AAIW transport (Sv) } & \multicolumn{3}{|c|}{ NADW transport (Sv) } & \multirow[t]{2}{*}{ Latitude range } \\
\hline & Total & Eastward & Westward & Total & Eastward & Westward & \\
\hline \multicolumn{8}{|l|}{$35^{\circ} \mathrm{W}$} \\
\hline $02 / 1993$ & -2.1 & 2.1 & -4.2 & 8.7 & 18.7 & -10.0 & $0.8^{\circ} \mathrm{S}-0.6^{\circ} \mathrm{N}$ \\
\hline $02 / 2002$ & -1.5 & 1.9 & -3.4 & - & - & - & $1.0^{\circ} \mathrm{S}-0.4^{\circ} \mathrm{N}$ \\
\hline $03 / 1994$ & -6.2 & 2.9 & -9.1 & 0.8 & 19.0 & -18.2 & $1.1^{\circ} \mathrm{S}-0.6^{\circ} \mathrm{N}$ \\
\hline $03 / 2001$ & -5.6 & 0.7 & -6.3 & - & - & - & $0.7^{\circ} \mathrm{S}-1.0^{\circ} \mathrm{N}$ \\
\hline $04 / 1996$ & -2.9 & 2.8 & -5.7 & $0.3^{1}$ & 16.4 & -16.1 & $1.0^{\circ} \mathrm{S}-1.0^{\circ} \mathrm{N}$ \\
\hline $04 / 2000$ & -5.3 & 0.7 & -6.0 & $-5.5^{1}$ & 12.5 & -18.0 & $1.0^{\circ} \mathrm{S}-1.0^{\circ} \mathrm{N}$ \\
\hline 06/1991 & 4.0 & 6.2 & -2.2 & -10.2 & 11.4 & -21.6 & $1.1^{\circ} \mathrm{S}-0.7^{\circ} \mathrm{N}$ \\
\hline $07 / 1999$ & 6.7 & 7.8 & -1.1 & $-9.7^{1}$ & 15.2 & -24.9 & $1.0^{\circ} \mathrm{S}-1.0^{\circ} \mathrm{N}$ \\
\hline $10 / 1990$ & -13.4 & 0.0 & -13.4 & - & - & - & $0.4^{\circ} \mathrm{S}-0.5^{\circ} \mathrm{N}$ \\
\hline $11 / 1992$ & -24.3 & 0.0 & -24.3 & 17.9 & 22.7 & -4.8 & $1.1^{\circ} \mathrm{S}-0.6^{\circ} \mathrm{N}$ \\
\hline \multicolumn{8}{|l|}{$28^{\circ} \mathrm{W}$} \\
\hline $01 / 2000$ & -6.1 & 0.4 & -6.5 & - & - & - & $1.0^{\circ} \mathrm{S}-0.0^{\circ} \mathrm{N}$ \\
\hline \multicolumn{8}{|l|}{$25.5^{\circ} \mathrm{W}$} \\
\hline $01 / 2000$ & -4.2 & 5.5 & -9.7 & - & - & - & $1.0^{\circ} \mathrm{S}-1.0^{\circ} \mathrm{N}$ \\
\hline \multicolumn{8}{|l|}{$23^{\circ} \mathrm{W}$} \\
\hline $07 / 1999$ & 0.1 & 5.6 & -5.5 & $-7.6^{4}$ & 12.9 & -20.5 & $1.0^{\circ} \mathrm{S}-1.0^{\circ} \mathrm{N}$ \\
\hline $01 / 2000$ & 0.9 & 6.3 & -5.4 & - & - & - & $1.0^{\circ} \mathrm{S}-1.0^{\circ} \mathrm{N}$ \\
\hline
\end{tabular}

For some sections no NADW transports could be estimated because too many profiles did not extend to $3900 \mathrm{~m}$. The transports (negative $\rightarrow$ westward) were derived from the LADCP data collected along cross-equatorial sections. $1 \mathrm{~Sv}$ is $10^{6} \mathrm{~m}^{3} \mathrm{~s}^{-1}$. The superscript numbers in the column of total NADW transports give the number of profiles with a maximum depth that is less than $3900 \mathrm{~m}$. One of them ends at $3192 \mathrm{~m}$, the others end between 3480 and $3560 \mathrm{~m}$.

velocity collected in the tropical Atlantic. Among them are the scales of $400-600 \mathrm{~m}$ which are typical for the equatorial jets in the upper $2500 \mathrm{~m}$ in the Atlantic (Gouriou et al., 1999; Johnson and Zhang, 2003). Scales in the upper range (about $1000 \mathrm{~m}$ ) indicate the absence of jets in a part of the water column. Scales in the lower range (about $100 \mathrm{~m}$ ) can be present within the jets or in a jet-free depth interval. In both cases the peak-to-peak amplitudes of the zonal velocity are smaller than the about $20 \mathrm{~cm} \mathrm{~s}^{-1}$ typical for the jets.

Observations at eight longitudes reveal that the jets in the Atlantic can have a zonal extent of at least $27^{\circ}(3000 \mathrm{~km}$, in the summer of 1997, Fig. 2A). Previously, Gouriou et al. (2001) came to the conclusion that the zonal extent may be $25^{\circ}$ (based on observations at only three longitudes). The larger zonal resolution increases the confidence that the derived larger value for the length scale is correct. In this and other sections a preference for west-east deepening of the jets and velocity peaks is apparent (Fig. 2). The depth change is mostly about $50 \mathrm{~m} / 10^{\circ}$ in the zonal averages, and can be as large as $320 \mathrm{~m} / 10^{\circ}$ (Table 2). The higher values are derived for surveys that only cover short distances ( $5^{\circ}$ or less). There are strong indications that the west to east deepening of the jets and velocity peaks may be largely concentrated between $35^{\circ}$ and $23^{\circ} \mathrm{W}$. This is the reason why some of the surveys of limited zonal extent can have large mean depth changes.

The large zonal extent of the jets and the changes of their depth along the equator are in general agreement with long vertically propagating linear waves (McCreary, 1984). For example, McCreary (1984) derived depth changes of about 

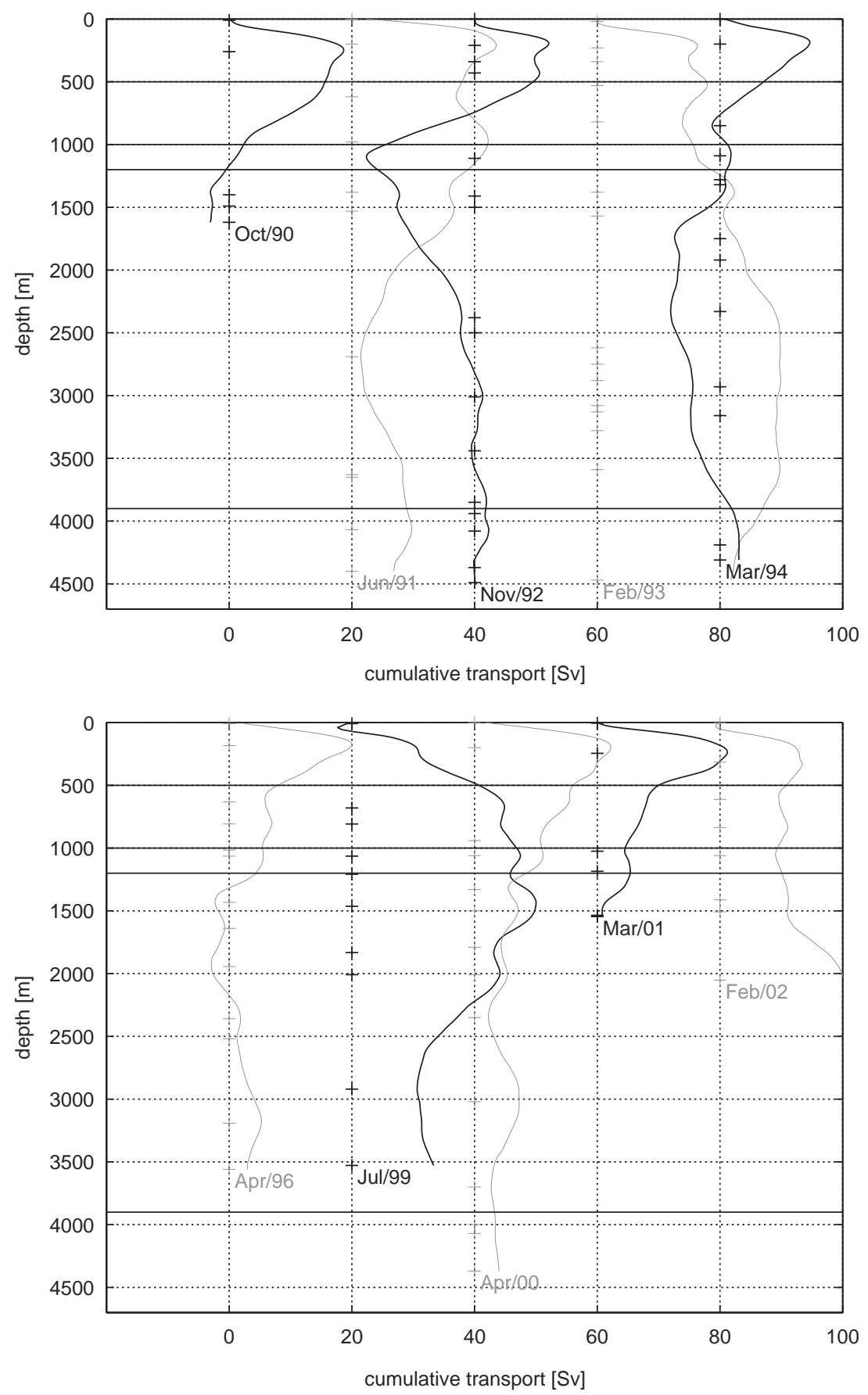

Fig. 6. Profiles of the zonal cumulative transport (integrated from top to bottom) at $35^{\circ} \mathrm{W}$ from observations with lowered ADCPs (Pegasus in February 1993). The profiles are shifted by $20 \mathrm{~Sv}\left(1 \mathrm{~Sv}=10^{6} \mathrm{~m}^{3} \mathrm{~s}^{-1}\right)$. The crosses indicate the depths where the direction of the transport changes. The straight lines indicate the boundaries chosen for the Antarctic Intermediate Water (500-1000 m) and North Atlantic Deep Water (1200-3900 m) layer. 
$140 \mathrm{~m} / 10^{\circ}$ and $380 \mathrm{~m} / 10^{\circ}$ for the first and third meridional mode of equatorially trapped Rossby waves (his Fig. 6A), respectively, and about $50 \mathrm{~m} / 10^{\circ}$ for Kelvin waves. These values are within the range of values derived here (Table 2). It has to be cautioned, however, that slopes as large as those derived for Rossby waves are only observed within a limited longitude range. The longitude dependence of the slopes indicates that the simple linear wave theory (aside from other limitations discussed below) is not sufficient to describe the characteristics of the jets. A possible reason for this may be topographic effects. On the equator the Mid-Atlantic Ridge covers two broad regions that are connected by a narrow ridge sloping from the Northeast to the Southwest (Fig. 1). The western region extends from $30^{\circ}$ to $22^{\circ} \mathrm{W}$, with a water depth of $2200-3400 \mathrm{~m}$. The eastern region extends from $19^{\circ}$ to $13^{\circ} \mathrm{W}$, with a water depth of, mostly, 2800-3200 m. In both longitude bands the smaller water depths are found within $0.5-1^{\circ}$ of the equator. The shallowest water depth, $1600 \mathrm{~m}$, is found near $0.5^{\circ} \mathrm{N}, 17^{\circ} \mathrm{W}$. The western region is within the longitude range where the depth change of the jets and peaks is larger, and closer to the values predicted by the linear wave theory (e.g., for three jets observed in July 1997, Fig. 2A, for some of the peaks observed in January 2000 and for one jet observed in March 2001). In the eastern region, only two jets reveal a relatively large depth change in the same section (near $13^{\circ} \mathrm{W}$ ). Consistent with the differences between the observations and the linear wave theory found here, several studies (e.g., Pedlosky, 2003; Muench and Kunze, 2000; Hua et al., 1997; Muench et al., 1994) have suggested that the linear wave theory alone is not sufficient to explain the jets. However, Rossby and Kelvin waves are likely to play a significant role.

The observations show that the profiles of the zonal velocity can have opposing jets at some depths and jets pointing in the same direction at other depths (Figs. 3 and 4). Such cases occur for profiles obtained in the same month of different years as well as for profiles obtained within 4 months of each other. In addition, during some surveys the jet structure is very strong and regular, whereas they are only poorly developed in other surveys. Firing (1987) reported that jets observed in a 16-month time series can disappear and reappear again at some depths, while some of those at other depths remain visible over most of the period of observation. Firing (1987) also showed that many of the jets shoaled $50 \mathrm{~m}$ over the time period, and that a vertical displacement occurred between 1980 and 1982/1983. According to Firing (1987) the latter could be, e.g., due to a local deepening of about $130 \mathrm{~m}$, or a local shoaling of $220 \mathrm{~m}$. Alternatively, it could be that the jets form, grow and decay in place, or that the jets change depth by decaying at one depth and forming at another depth (Firing, 1987). The latter two possibilities could be the explanation for the profiles with poorly developed jets in part of the water column. Taken together these observations indicate that the temporal variability of the jets is complicated.

The jets and velocity peaks have a significant impact on estimates of the transports of the Antarctic Intermediate Water (AAIW) and the North Atlantic Deep Water (NADW), since they are dynamically independent of the vertical water mass distribution, and since their vertical extent is smaller than the thickness of the layers occupied by the water masses. For this reason both eastward and westward transports can occur at the same time within a water mass (Table 3 ).

In the AAIW layer the total transport is in the range of -24.3 to $6.7 \mathrm{~Sv}$. During most surveys the transport of AAIW is westward. Only in June 1991 and July 1999 the total transports were eastward. In July 1997 no transport could be estimated, but the flow structure indicates that the transport would be westward. This indicates that an annual cycle may exist, and that interannual variability may be important. Current meter records presented in various studies (e.g., Weisberg and Horigan, 1981; Eriksen, 1985; Thierry, 2000; Send et al., 2002) allow the identification of important time scales associated with the variability of the zonal flow. The mooring records for the zonal velocity presented by Eriksen (1985) indicate that a period of 1-2 months with a peak-to-peak amplitude of about $10 \mathrm{~cm} \mathrm{~s}^{-1}$ can exist at depths of 500-600 m (primarily during the second half of the year, i.e. at the time when tropical instability 
waves are strong). The importance of this observation is limited since Eriksen's moorings were in the Pacific. The other mooring records (Weisberg and Horigan, 1981; Thierry, 2000; Send et al., 2002) were located in the Atlantic and they do not show such a mesoscale variability in the zonal velocity. The mooring records available to Thierry (2000) have some higher-periodic variability, but the largest peak-to-peak amplitudes of about $5 \mathrm{~cm} \mathrm{~s}^{-1}$ occur in the first half of the year. It has to be cautioned here, that only Weisberg and Horigan had moorings in the depth range above $1000 \mathrm{~m}$. If variability with mesoscale periods is present in the mooring records it is characterized by an amplitude that is smaller than the amplitude associated with the jets. Therefore mesoscale variability does not play a significant role for the discrepancies between the sections obtained during the same months of different years. It seems more likely that these discrepancies are due to interannual variabilities. The transport estimates from these surveys and the knowledge about the mesoscale variability suggest that an annual cycle exists. These results are consistent with velocity observations published earlier. For example, quasi-Lagrangian observations from profiling floats showed that the westward flow in July 1997 continued until November 1997 in the lower part of the AAIW layer (Molinari et al., 1999; Schmid et al., 2001). The flow then reversed to eastward until the floats left the equatorial band in January 1998. Ponte (1989) showed a Pegasus profile obtained in January 1989 at $30^{\circ} \mathrm{W}$ with eastward and westward jets governing the flow in the AAIW layer, resulting in a mean flow towards the east. This is consistent with the quasi-Lagrangian float observations obtained 9 years later, especially since the lower part of the AAIW layer has eastward velocities (as found here for January 2000). Boebel et al. (1999) combined earlier observations (from 1974 to 1994, various instruments; Weisberg et al., 1980; Weisberg, 1980; Richardson and Schmitz, 1993; Schott et al., 1998) with newer observations (from 1994 to 1995, RAFOS floats). Most of these observations are from the western Atlantic $\left(22-45^{\circ} \mathrm{W}\right)$. Boebel et al. (1999) concluded that the water in the AAIW core flows eastward in April to July and westward in
August to November, whereas it can be transport either way in the other months. While direct comparisons of their and our results are difficult, since they were derived for different depth ranges, all observations suggest that eastward transports of AAIW occur in early summer (and sometimes also in spring), whereas westward transports prevail for the rest of the year.

Because of the large temporal variability, it was not attempted to use the transports in Table 3 to estimate the annual mean of the transport of AAIW along the equator. But it is noted that the prevalence and the larger magnitude of westward transports indicates that the mean transport may be westward. An estimate of the mean zonal transport across $35^{\circ} \mathrm{W}$ between 700 and $900 \mathrm{~m}$ was obtained by Schott et al. (2003). They derived a westward transport of $10 \mathrm{~Sv}$ on the basis of twelve LADCP sections and an assumption that an annual and a semi-annual cycle dominate the variability of the transport.

In contrast to the evidence from the velocity observations, studies of water mass distributions have indicated that the mean transport of AAIW along the equator may be weaker than the velocity-based results suggest. Maps of the salinity on two adjacent isopycnals in the AAIW layer (27.2 and $27.3 \sigma_{\Theta}$ ) give no indications for either eastward or westward spreading of this water mass along the equator (Tsuchiya et al., 1994; Suga and Talley, 1995). Warner and Weiss (1992) derived a map of the distributions chlorofluoromethane (CFM) concentration on the isopycnal $27.2 \sigma_{\Theta}$ (their Fig. 11) and analyzed two CFM sections along the prime meridian. Their map shows a broad region of higher concentrations near the equator. Within this region the concentration decreases towards the east, which they interpreted as a sign for eastward flow. The highest concentrations are found south of the equator at the latitude of the Southern Intermediate Countercurrent (SICC, see Stramma and Schott (1999) for a review and Schmid et al. (2003) for additional details). The map by Warner and Weiss (1992) indicates that the distance between the maximum in the tongue and the equator decreases from west to east. At the prime meridian the maximum is wide enough to include the equator. This may be 
due to horizontal mixing of equatorial water (lower CFM concentration) with the water in the eastward SICC (higher CFM concentration) that can cause a faster reduction of the CFM concentration in the SICC and slower reduction of the CFM concentration on the equator. Signs for water exchanges consistent with this process were detected in RAFOS trajectories by Boebel et al. (1999). The distribution observed by Warner and Weiss (1992) can exist during periods of eastward or westward equatorial flow if the mixing is strong enough, i.e., the change of CFM concentrations along the equator are not sufficient to determine direction of the mean equatorial flow.

Model results by Jochum and Malanotte-Rizzoli (2003) also suggest that the zonal AAIW transport is governed by an annual cycle and that its mean transport along the equator is weak. It has to be noted that the vertical resolution of their model (20 levels between 100 and $3000 \mathrm{~m}$ ) is not sufficient to simulate the jets. This may be why the zonal velocities in their model between the Equatorial Undercurrent and $1500 \mathrm{~m}$ have peaks of about $10 \mathrm{~cm} \mathrm{~s}^{-1}$, whereas the observed velocity peaks can have $20-30 \mathrm{~cm} \mathrm{~s}^{-1}$. If the jets are persistent features, as suggested by some observations (see Section 1), then their absence in the model can prevent the derivation of realistic mean transports on a year-by-year basis. In this case only long-term means of the transport may be realistic, but only if the transports due to the jets cancel out.

In the NADW layer the total transports range from -10.2 to $17.9 \mathrm{~Sv}$ (Table 3 ). The observations indicate that an annual cycle may exist at $35^{\circ} \mathrm{W}$, with westward total transports in the summer and eastward total transports in the winter. The uncertainty of the inference of an annual cycle for the transport of NADW is larger than for the transport of AAIW because fewer sections were available. However, it is noted that the total transports in the AAIW layer are often of opposite sign when compared with the total transport of the NADW layer (the correlation coefficient is -0.86 ) which increases our confidence in the presence of an annual cycle of the transport in the NADW layer. Also, this annual cycle is consistent with independent observations in the central equatorial Atlantic: Thierry (2000) reported the observation of annual cycles in the Romanche Fracture Zone (at $0.7^{\circ} \mathrm{N}, 14.8^{\circ} \mathrm{W}$, Fig. 1) and the Chain Fracture Zone (at $0.9^{\circ} \mathrm{S}, 13.5^{\circ} \mathrm{W}$ ) using current meter records obtained at depths of 1700 and $2000 \mathrm{~m}$ between November 1992 and October 1994. The peak-to-peak amplitude associated with this signal was $10-20 \mathrm{~cm} \mathrm{~s}^{-1}$, and the flow was mostly eastward in fall/winter and mostly westward in spring/ summer, which is consistent with our result.

A similar annual cycle was also detected in the zonal velocity fields of a model experiment at depth of $1875 \mathrm{~m}$ between $5^{\circ}$ and $35^{\circ} \mathrm{W}$ on the equator (Böning and Schott, 1993, their Fig. 7. The vertical grid spacing at this depth is $250 \mathrm{~m}$, which is not sufficient to fully resolve the jets. Therefore the annual cycle in the model cannot be explained by the jets. Based on a time series from current meters at four depths $(1300,1500,1700$ and $1900 \mathrm{~m}$ ), Send et al. (2002) reported that no seasonal reversals of the zonal flow occurred on the equator at $36^{\circ} \mathrm{W}$ (Fig. 1) during a 20 -month period (October 1992-May 1994). However, the current meter at $1500 \mathrm{~m}$ recorded variations of the zonal velocity with a peak-to-peak amplitude of $10-30 \mathrm{~cm} \mathrm{~s}^{-1}$ and periods of $4-6$ months. This range of periods is comparable to results presented by Weisberg and Horigan (1981) who reported periods of 4-8 months in the Gulf of Guinea (at 869 and $1284 \mathrm{~m}$, their record at $1822 \mathrm{~m}$ is too short to detect such periods). Throughout the first 460 days of the current meter record presented by Send et al. (2002) the amplitude of these variations was not large enough to cause reversals of the zonal flow.

The discrepancy between the current meter records available to Thiery (2000; reversals of the flow at an annual period) and Send et al. (2002; no reversals of the flow at an annual period) is very interesting, since they were obtained for nearly the same time periods. It seems possible that the variability in the central Atlantic may have a different characteristic than the variability in the western Atlantic. This would mean that the similarity of the annual cycle of the NADW transports derived from the synoptic sections in the western Atlantic and the current meter records in the central Atlantic is only a coincidence that may, in fact, be caused by interannual variabilities 
in the western Atlantic (as suggested by Send et al., 2002). However, this does not explain the quasisemiannual period found in the $1500 \mathrm{~m}$ mooring.

No conclusive theory has been presented that explains the differences between the current meter records obtained at these different locations. Several processes could cause such differences: (1) Effects due to the close proximity of the western boundary with its own dynamics may have a large enough influence to overshadow an annual cycle at $36^{\circ} \mathrm{W}$. This could be caused by an offshore recirculation of the Deep Western Boundary Current. McCartney (1993) summarized and confirmed earlier studies that indicate that such a recirculation exists. Rhein et al. (1995) analyzed tracers and transports which also support a recirculation of the Deep Western Boundary Current. They found, for example, that the transport of the shallow upper NADW in the Deep Western Boundary Current increased from 4 to $11 \mathrm{~Sv}$ between $47^{\circ}$ and $35^{\circ} \mathrm{W}$. Based on their schematic, the recirculation is likely to have a significant impact on the velocities observed on the equator at $36^{\circ} \mathrm{W}$. (2) The Mid-Atlantic Ridge may prevent the penetration of an annual wave signal from the eastern into the western basin. Barnier (1988) performed a model study in the North Atlantic that indicates that the Mid-Atlantic Ridge can block planetary waves at mid-latitudes. A result of this is a generation of planetary waves with different properties on the western side of the ridge. It has to be cautioned, however, that the impact of the Mid-Atlantic Ridge on equatorially trapped waves may be different, because their propagation has a large vertical component. A study of velocities from a general circulation model by Li and Chang (1999) shows that an annual cycle is present on the equator on both sides of the Mid-Atlantic Ridge, but there are signs that the ridge has an impact on the phase of the waves. As in the model fields used by Böning and Schott (1993) the vertical grid spacing is too large to resolve the jets (it is about $500 \mathrm{~m}$ at the depth of the NADW).

It is not clear at this time if the observations of an annual cycle are due to a variability of the jets, or due to a variability of currents with a larger vertical extent than the jets. The model studies by
Böning and Schott (1993), Li and Chang (1999), and Jochum and Malanotte-Rizzoli (2003) are in favor of the latter, but their validity to address this question is limited because of the insufficient vertical resolution. The anti-correlation of the AAIW and NADW transports also supports the concept that currents of larger vertical scales may be the primary cause for the annual cycle. This is consistent with results from some earlier studies which reported quite stable jet structures over extended periods of time (one year or even longer; e.g., Muench et al., 1994; Send et al., 2002), which indicates that interannual rather than shorterperiodic variability might give rise to the differences between the jet structures observed in profiles from the same season and longitude (Figs. 3 and 4).

An experiment to address the open questions about the jets would have to involve current meter moorings at several longitudes along the equator (every $5-10^{\circ}$, with measurements on both sides of the Mid-Atlantic Ridge) with a vertical resolution of at least $50 \mathrm{~m}$. Numerical models would need a similar or higher vertical resolution to be able to simulate the jets.

\section{Acknowledgments}

We want to thank Christopher Meinen and Rick Lumpkin for helpful suggestions and Friedrich A. Schott for making the data from several cruises available to us. We are also grateful for the software to estimate tidal currents which was provided by Eric Firing and colleagues. This work is partially sponsored by NOAA's Office of Global Programs.

\section{References}

Barnier, B., 1988. A numerical study on the influence of the Mid-Atlantic Ridge on non-linear first mode baroclinic rossby waves generated by seasonal winds. Journal of Physical Oceanography 18 (3), 417-433.

Boebel, O., Schmid, C., Zenk, W., 1999. Kinematic elements of Antarctic Intermediate Water in the western South Atlantic. In: Zenk, W., Peterson, R.G., Lutjeharms, J.R.E. (Eds.), New Views of the Atlantic. Deep-Sea Research II 46 (1-2), 355-392. 
Böning, C., Schott, F.A., 1993. Deep currents and the eastward salinity tongue in the Equatorial Atlantic: results from an Eddy-resolving, Primitive Equation Model. Journal of Geophysical Research 98 (C4), 6991-6999.

Bourlès, B., Gouriou, Y., Eldin, G., du Penhoat, Y., Freudenthal, S., Dewitte, B., Gallois, F., Chuchla, R., Baurand, F., Aman, A., Kouadio, G., 2003. The deep currents in the Eastern Equatorial Atlantic Ocean. Geophysical Research Letters 30 (5), 2/1-4.

Egbert, G.D., Bennet, A.F., Foreman, M.G.G., 1994. TOPEX/ POSEIDON tides estimated using a Global Inverse Model. Journal of Geophysical Research 99 (C12), 24,821-24,852.

Eriksen, C.C., 1981. Deep currents and their interpretation as equatorial waves in the Western Pacific Ocean. Journal of Physical Oceanography 11 (1), 48-70.

Eriksen, C.C., 1985. Moored observations of deep lowfrequency motions in the Central Pacific Ocean: vertical structure and interpretation as equatorial waves. Journal of Physical Oceanography 15 (8), 1085-1113.

Firing, E., 1987. Deep zonal currents in the central equatorial Pacific. Journal of Marine Research 45 (4), 791-812.

Fischer, J., Visbeck, M., 1993. Deep velocity profiling with selfcontained ADCPs. Journal of Atmospheric and Oceanic Technology 10 (10), 764-773.

Gouriou, Y., Bourlès, B., Mercier, H., Chuchla, R., 1999. Deep jets in the Equatorial Atlantic Ocean. Journal of Geophysical Research 104 (C9), 21,217-21,226.

Gouriou, Y., Andrié, C., Bourlès, B., Freudenthal, S., Arnault, S., Aman, A., Eldin, G., du Penhoat, Y., Baurand, F., Gallois, F., Chuchla, R., 2001. Deep circulation in the Equatorial Atlantic Ocean. Geophysical Research Letters 28 (5), 819-822.

Hacker, P., Firing, E., Wilson, W.D., Molinari, R.L., 1996. Direct observations of the Current Structure East of the Bahamas. Geophysical Research Letters 23 (10), $1127-1130$.

Hua, B.L., Moore, D.W., Gentil, S.L., 1997. Inertial nonlinear equilibration of equatorial flows. Journal of Fluid Mechanics 331, 345-371.

Jochum, M., Malanotte-Rizzoli, P., 2003. The flow of AAIW along the equator. In: Goni, G., Malanotte-Rizzoli, P. (Eds.), Interhemispheric Water Exchange in the Atlantic Ocean, Elsevier Oceanographic Series, vol. 68. Elsevier, New York, pp. 193-212.

Johnson, G.C., Zhang, D., 2003. Structure of Atlantic Ocean equatorial deep jets. Journal of Physical Oceanography 33 (3), 600-609.

Johnson, G.C., Kunze, E., McTaggart, K.E., Moore, D.W., 2002. Temporal and spatial structure of the equatorial deep jets in the Pacific Ocean. Journal of Physical Oceanography 32 (12), 3396-3407.

Li, X., Chang, P., 1999. Mixing induced by the Atlantic Equatorial Wave Activity in an Eddy-resolving OGCM. Journal of Geophysical Research 104 (C6), 13,303-13,315.

Luyten, J.R., Swallow, F.C., 1976. Equatorial undercurrents. Deep-Sea Research 23 (10), 999-1001.
McCartney, M.S., 1993. Crossing of the Equator by the Deep Western Boundary Current in the Western Atlantic Ocean. Journal of Physical Oceanography 23 (9), 1953-1974.

McCreary, J.P., 1984. Equatorial beams. Journal of Marine Research 42 (2), 395-430.

Molinari, R.L., Garzoli, S.L., Schmitt, R.W., 1999. Equatorial currents at $1000 \mathrm{~m}$ in the Atlantic Ocean. Geophysical Research Letters 26 (3), 361-363.

Muench, J.E., Kunze, E., 2000. Internal wave interactions with equatorial deep jets. Part II: Acceleration of the jets. Journal of Physical Oceanography 30 (8), 2099-2110.

Muench, J., Kunze, E., Firing, E., 1994. The potential vorticity structure of equatorial deep jets. Journal of Physical Oceanography 24 (2), 418-428.

Pedlosky, 2003. A theory of equatorial deep jets. WHOI Contribution No. 10639, 22pp.

Ponte, R.M., 1989. A simple model for deep equatorial zonal currents forced at lateral boundaries. Journal of Physical Oceanography 19 (12), 1881-1891.

Ponte, R.M., Luyten, J., Richardson, P.L., 1990. Equatorial deep jets in the Atlantic Ocean. Deep-Sea Research 37 (4), 711-713.

Rhein, M., Stramma, L., Send, U., 1995. The Atlantic Deep Western Boundary Current: water masses and transports near the equator. Journal of Geophysical Research 100 (C2), 2441-2457.

Richardson, P.L., Schmitz, W.J., 1993. Deep cross-equatorial flow in the Atlantic measured with SOFAR floats. Journal of Geophysical Research 98 (C5), 8371-8387.

Schmid, C., Molinari, R.L., Garzoli, S., 2001. New observations of the intermediate depth circulation in the Tropical Atlantic. Journal of Marine Research 59 (3), 281-312.

Schmid, C., Garraffo, Z., Johns, E., Garzoli, S.L., 2003. Pathways and variability at intermediate depths in the tropical Atlantic. In: Goni, G., Malanotte-Rizzoli, P. (Eds.), Interhemispheric Water Exchange in the Atlantic Ocean, Elsevier Oceanographic Series, vol. 68. Elsevier, New York, pp. 233-268.

Schott, F.A., Fischer, J., Stramma, L., 1998. Transports and pathways of the upper-layer circulation in the Western Tropical Atlantic. Journal of Physical Oceanography 28 (10), 1904-1928.

Schott, F.A., Dengler, M., Brandt, P., Affler, K., Fischer, J., Bourlès, B., Gouriou, Y., Molinari, R.L., Rhein, M., 2003. The zonal currents and transports at $35^{\circ} \mathrm{W}$ in the Tropical Atlantic. Geophysical Research Letters 30 (7), I 1-4 10.1029/2002GL016849.

Send, U., Eden, C., Schott, F., 2002. Atlantic Equatorial Deep jets: space-time structure and cross-equatorial fluxes. Journal of Physical Oceanography 32 (3), 891-902.

Stramma, L., England, M., 1999. On the water wasses and mean circulation of the South Atlantic Ocean. Journal of Geophysical Research 104 (C9), 20,863-20,883.

Stramma, L., Schott, F.A., 1999. The mean flow field of the Tropical Atlantic Ocean. In: Zenk, W., Peterson, R.G., Lutjeharms, J.R.E. (Eds.), New Views of the Atlantic. Deep-Sea Research II, 46 (1-2), 279-303. 
Suga, T., Talley, L.D., 1995. Antarctic intermediate water Circulation in the tropical and subtropical South Atlantic. Journal of Geophysical Research 100 (C7), $13,441-13,453$.

Thierry, V., 2000. Observation et Modélisation de la Variabilité Saisonnière dans l'océan Atlantique Equatorial Profond. Ph.D. Thesis, Université de Brest, 211pp.

Tsuchiya, M., Talley, L.D., McCartney, M.S., 1994. Watermass distributions in the Western South Atlantic; a section from South Georgia Island (54S) Northward across the Equator. Journal of Marine Research 52, 55-81.

Wang, D., Moore, D.W., Rothstein, L.M., 1994. Exact solutions of Kawase's Linear Model of Deep Ocean Circulation. Journal of Physical Oceanography 24 (10), $2188-2195$.
Warner, M.J., Weiss, R.F., 1992. Chlorofluoromethanes in South Atlantic Antarctic Intermediate Water. Deep-Sea Research 39 (11/12), 2053-2075.

Weisberg, R.H., 1980. Equatorial waves during GATE and their relation to the mean zonal circulation. Deep-Sea Research 26 (2), 179-198.

Weisberg, R.H., Horigan, A.M., 1981. Low-frequency variability in the Equatorial Atlantic. Journal of Physical Oceanography 11 (7), 913-920.

Weisberg, R.H., Miller, L., Horigan, A., Knauss, J., 1980. Velocity observations in the equatorial thermocline during GATE. Deep-Sea Research 26 (2), 217-248.

Wunsch, C., 1977. Response of an equatorial ocean to a periodic monsoon. Journal of Physical Oceanography 7 (4), 497-511. 